\title{
Reduced fetal cerebral oxygen consumption is associated with abnormal white matter in newborns with congenital heart disease
}

Prakash Muthusami ${ }^{1 *}$, Sujana Madathil ${ }^{1}$, Susan Blaser ${ }^{1}$, Edgar Jaeggi $^{1}$, Lars Grosse-Wortmann ${ }^{1}$, Shi-Joon Yoo ${ }^{1}$, John Kingdom², Edward J Hickey², John G Sled ${ }^{1}$, Christopher Macgowan' ${ }^{1}$, Steven Miller ${ }^{1}$, Mike Seed ${ }^{1}$

From 18th Annual SCMR Scientific Sessions

Nice, France. 4-7 February 2015

\section{Background}

Congenital heart disease (CHD) is associated with brain dysmaturation, increased risk of perioperative white matter (WM) injury and neurodevelopmental delay (1). Fetal Doppler studies have shown altered cerebrovascular flow dynamics in CHD, suggesting 'brain-sparing physiology'. We sought to determine whether postnatal cerebral WM microstructural abnormality relates to abnormal fetal hemodynamics.

\section{Methods}

This prospective IRB approved study included 15 fetuses with CHD and 25 normal fetuses at 36 gestational weeks, who underwent phase-contrast MRI using metric

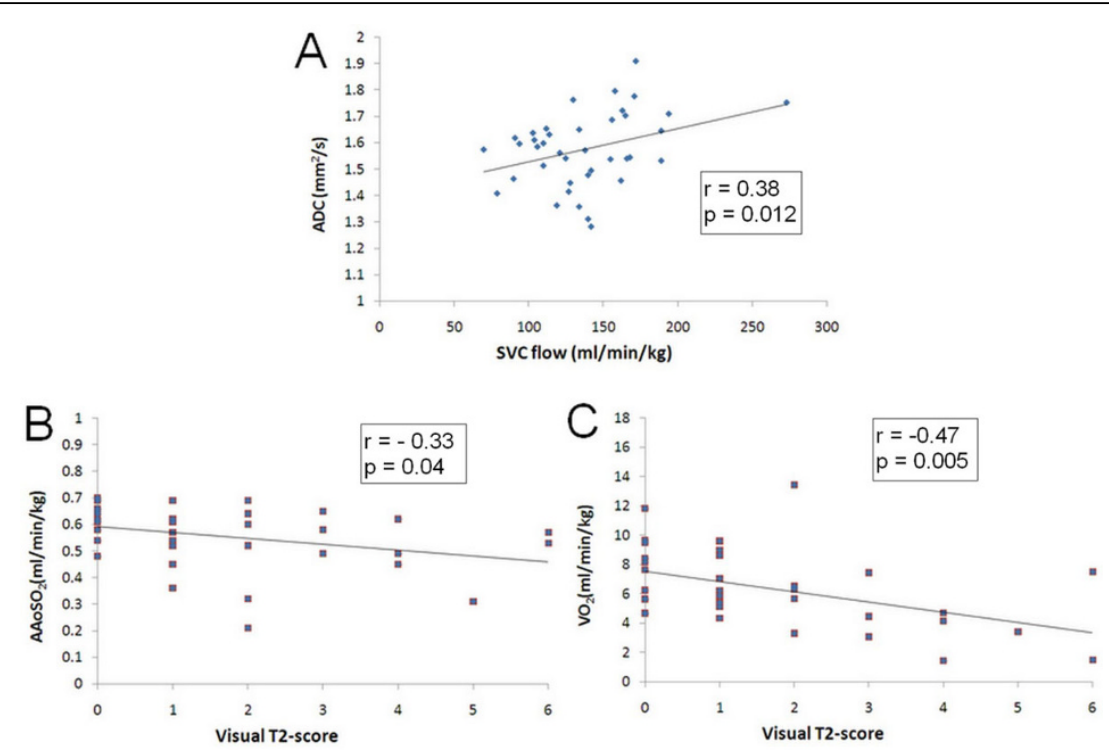

Figure 1 Relations between fetal hemodynamics and neonatal white matter (WM) changes in congenital heart disease. A) Positive correlation between fetal SVC flow and neonatal WM apparent diffusion coefficient. B) Negative correlation between fetal ascending aortic oxygen saturation and neonatal WM T2-score. C) Negative correlation between fetal oxygen consumption and neonatal WM T2-score. Pearson's $r$ and p-values are in accompanying boxes.

${ }^{1}$ The Hospital for Sick Children, Toronto, ON, Canada

Full list of author information is available at the end of the article

(c) 2015 Muthusami et al; licensee BioMed Central Ltd. This is an Open Access article distributed under the terms of the Creative 
Table 1

\begin{tabular}{|c|c|c|c|c|}
\hline & NORMAL $(N=25)$ & $\mathrm{CHD}(\mathrm{N}=15)$ & $\mathrm{p}$-value & \\
\hline \multicolumn{2}{|c|}{ Age at MRI (Days) } & 5.24 & 4.93 & 0.85 \\
\hline \multicolumn{2}{|c|}{ Corrected gestational age at MRI (Weeks) } & 39.9 & 39 & 0.06 \\
\hline \multicolumn{2}{|c|}{ White matter T2-score $(0-6)$} & 1.16 & 3.08 & 0.002 \\
\hline \multirow[t]{3}{*}{$\mathrm{ADC}(\times 10-6 \mathrm{~mm} 2 / \mathrm{sec})$} & Centrum semiovale & 1461.7 & 1494.3 & 0.20 \\
\hline & Frontal deep white matter & 1716.6 & 1818.2 & 0.02 \\
\hline & Parietal deep white matter & 1668.1 & 1783.3 & 0.008 \\
\hline \multicolumn{2}{|c|}{ SVC flow $(\mathrm{ml} / \mathrm{min} / \mathrm{kg})$} & 134.4 & 144.6 & 0.43 \\
\hline \multicolumn{2}{|c|}{$\mathrm{AAOSO} 2(\%)$} & 58 & 49 & 0.02 \\
\hline \multicolumn{2}{|c|}{$\mathrm{VO} 2(\mathrm{ml} / \mathrm{min} / \mathrm{kg})$} & 7.12 & 5.03 & 0.02 \\
\hline \multicolumn{2}{|c|}{ CVO2 (ml/min/kg) } & 4.23 & 2.98 & 0.03 \\
\hline
\end{tabular}

AAoSO2 = Ascending aortic oxygen saturation; $\mathrm{ADC}=$ Apparent diffusion coefficient; $\mathrm{CHD}=$ Congenital heart disease; $\mathrm{CVO} 2$ = Cerebral oxygen consumption; SVC $=$ Superior vena cava; $\mathrm{VO} 2=$ Fetal oxygen consumption.

optimized gating and T2-mapping for MR oximetry in the major vessels, according to our previously published technique (2). Neonatal MRI was performed at 5 days (SD 5 days) including diffusion tensor imaging and axial T2W-FSE. Apparent diffusion coefficient (ADC) values were measured in the centrum semiovale (CSO), frontal and parietal deep WM, and mean cerebral WM-ADC was calculated. Visual scoring of WM was performed using a 0 - 6 scale (number of T2-hyperintense regions).

\section{Results}

Ascending aortic oxygen saturation $\left(\mathrm{AAoSO}_{2}\right), \mathrm{VO}_{2}$ and $\mathrm{CVO}_{2}$ were significantly lower in the CHD group (49\% vs. $58 \%, \mathrm{p}=0.02 ; 5.03 \mathrm{ml} / \mathrm{min} / \mathrm{kg}$ vs. $7.12 \mathrm{ml} / \mathrm{min} / \mathrm{kg}$, $\mathrm{p}=0.02$ and $2.98 \mathrm{ml} / \mathrm{min} / \mathrm{kg}$ vs. $4.23 \mathrm{ml} / \mathrm{min} / \mathrm{kg}, \mathrm{p}=0.03$, respectively). Although mean SVC flow (a surrogate for cerebral flow) was higher in CHD fetuses, the difference was not statistically significant. However, there was a moderately strong correlation between SVC flow and mean cerebral WM-ADC (Pearson's $r=0.38, p=0.012$ ) (Figure 1a). ADC was higher in CHD neonates in the frontal WM (by $6.9 \%, \mathrm{p}=0.008$ ), parietal WM (by $5.9 \%$, $\mathrm{p}=0.02$ ), and CSO (by $2.3 \%$, not statistically significant). Visual T2-score was significantly higher in CHD neonates ( 3.08 vs. $1.16, \mathrm{p}=0.002$ ), with a negative correlation with $\mathrm{AAoSO}_{2}(\mathrm{r}=-0.33, \mathrm{p}=0.04)$ and $\mathrm{VO}_{2}(\mathrm{r}=-0.47$, $\mathrm{p}=0.005)$ (Figure $1 \mathrm{~b}$ and $1 \mathrm{c})$.

\section{Conclusions}

We conclude that neonatal WM abnormalities in CHD are due to reduced fetal oxygenation. The correlation between more severe WM abnormality and elevated SVC flow, a known marker of acute fetal hypoxia (the "brain sparing" response) is further evidence that WM changes are driven by reduced cerebral oxygenation in utero.

\section{Funding}

This study was funded through an operating grant from the CIHR and a PHN New Scholar Award (NIH).

\section{Authors' details}

${ }^{1}$ The Hospital for Sick Children, Toronto, ON, Canada. ${ }^{2}$ Mount Sinai Hospital, Toronto, ON, Canada.

Published: 3 February 2015

\section{References}

1. Dimitropoulos A, et al: Brain injury and development in newborns with critical congenital heart disease. Neurology 2013, 81(3):241-8.

2. Sun $L$, et al: Comprehensive human fetal hemodynamic assessment by phase contrast MRI and MR oximetry. ISMRM Milan; 2014, Abstract.

doi:10.1186/1532-429X-17-S1-P201

Cite this article as: Muthusami et al:: Reduced fetal cerebral oxygen consumption is associated with abnormal white matter in newborns with congenital heart disease. Journal of Cardiovascular Magnetic

Resonance 2015 17(Suppl 1):P201.

\section{Submit your next manuscript to BioMed Central and take full advantage of:}

- Convenient online submission

- Thorough peer review

- No space constraints or color figure charges

- Immediate publication on acceptance

- Inclusion in PubMed, CAS, Scopus and Google Scholar

- Research which is freely available for redistribution

Submit your manuscript at www.biomedcentral.com/submit 